Arch. Met. Geoph. Biocl., Ser. A 33, 345--354 (1985)

ARCHIVES

FOR METEOROLOGY, GEOPHYSICS, AND

BIOCLIMATOLOGY

(C) by Springer-Verlag 1985

551.525 .5

Department of Geological Sciences, University of Michigan, Ann Arbor, Michigan, U.S.A.

\title{
A Model of Near-Surface Coupled-Flow Effects on the Diurnal Thermal Regime of a Peat-Covered Palsa
}

\author{
S. Outcalt and F. Nelson \\ With 6 Figures \\ Received July 23, 1984
}

\section{Summary}

The thermal regime in the moist surficial peat layer of a palsa, measured during a clear and calm July day in arctic Alaska, indicates that coupled heat and water flow retard ablation of the ice core. A simulation model of coupled-flow effects was constructed using rough estimates of meteorological boundary conditions and material properties. The model indicates that ablation is inhibited by advection of cold water above the ice/peat interface, and by internal evaporation near the surface. Evaporation also limits thermal maxima near the surface; because the ratio of the heat of evaporation to the heat of fusion is approximately 7.5 , the coupled-flow regime effectively retards ablation of the palsa's ice core.

\section{Zusammenfassung}

Ein Modell der gekoppelten Stromeffekte in Bodennähe auf den Tagesgang der Temperatur in einem torfbedeckten Pals

Das Temperaturregime in der feuchten, oberflächennahen Torfschicht eines Pals wurde während eines klaren und windstillen Julitages in der Arktis von Alaska vermessen. Es wird gezeigt, daß der gekoppelte Wärme- und Wasserstrom die Ablation des Eiskernes verzögert. Ein Simulationsmodell der gekoppelten Stromeffekte wurde konstruiert, wobei grobe Abschätzungen der meteorologischen Grenzbedingungen und der Bodenbeschaffenheit angebracht wurden. Das Modell deutet an, daß die Ablation durch Advektion von kaltem Wasser oberhalb der Eis-Torf-Grenzschicht und durch interne Verdunstung nahe der Oberfläche behindert wird. Verdunstung beschränkt außerdem die Temperaturmaxima nahe der Oberfläche. Da das Verhältnis der latenten Wärmen der Verdunstung und der Sublimation ungefähr 7,5 beträgt, verzögert das gekoppelte Stromregime effektiv die Ablation des Eiskernes der Pals. 


\section{Introduction}

The unusual thermal properties of peat are widely recognized as an important factor controlling the distribution of permafrost $[7,8]$. However, little has been done to elucidate the physical processes involved in heat transfer within peat incorporated in or overlying permafrost. In a related paper [3], we reported on a short-term, high-frequency temperature series obtained from the peat layer overlying a man-induced permafrost feature.

Temperature observations were obtained in eight shallow cores on and near a peat-covered palsa at Toolik Lake, Alaska $\left(68^{\circ} 38^{\prime} \mathrm{N}, 149^{\circ} 37^{\prime} \mathrm{W}\right)$ during a 24-hour period of calm and clear weather in late July, 1980. The data were collected at depths of $0,1,5,10$ and $20 \mathrm{~cm}$ and analyzed using finitedifference methods. Computation of effective thermal diffusivity yielded near-zero and, in some cases, negative values during periods of surface heating. Heat-transfer processes within the peat cover apparently minimize heat flux to the melting ice/peat interface, and therefore retard ablation of the ice core in summer. These observations are supported by repeated measurements of summit elevations on five palsas at the site between July 1980 and August 1983; only moderate $(1-18 \mathrm{~cm})$ cumulative ablation of the ice cores occurred during this period. In order to gain further insight into processes occurring in the peat mantle, a moist core site (Core 20) near one palsa's summit (Fig. 1) was selected for simulation of coupled-flow effects.

The temperature observations from Core 20 are plotted at hourly intervals (zero hour set at 20:10 Alaska Standard Time on 23 July 1980) in Fig. 2. The warming event, which occurred during the latter half of the time series at $0-10 \mathrm{~cm}$, is simultaneous with cooling at a depth of only $20 \mathrm{~cm}$; neither this or the near-zero and negative values of effective diffusivity are typical of a conductive heat-transfer system. Two processes could produce this effect: internal evaporation and cold-water advection. To ascertain the relative magnitudes of these processes, a simulation model was employed, using published data for the thermal properties of the substances of interest.

\section{Simulation}

The model employed in the analysis is similar to one used to simulate needle-ice growth and ablation [4]. Sections 2.1 through 2.8 outline the structure and specifications of the model.

\subsection{Lower Boundary}

Eleven calculation nodes, evenly spaced at $5-\mathrm{cm}$ intervals from the surface $(0 \mathrm{~cm})$ to the ice-peat contact $(50 \mathrm{~cm})$ were used in the calculations. The 




Fig. 1. Overview of instrumented palsa. Arrow indicates location of Core 20. July, 1980



Fig. 2. Observed thermal time series in Core 20

temperature at $50 \mathrm{~cm}$ was set at $-0.01^{\circ} \mathrm{C}$ and assigned a soil-water tension of $125 \mathrm{~cm}$, consistent with its location at a thawing interface. Freeze-thaw effects were not included, and both temperature and soil-water head values were held constant throughout the simulation. 


\subsection{Upper Boundary}

Linear interpolation was applied to the hourly surface temperatures to create a time series of values at 10-minute intervals; this was used to force the model at the upper boundary. The atmospheric dewpoint was assumed to be $10^{\circ} \mathrm{C}$, and a constant vapor density was calculated using this dewpoint. Changes in the surface water volume fraction were calculated as the sum of the water flux toward the surface from the atmosphere, and from the peat. These calculations utilized the dewpoint level $Z_{a}(200 \mathrm{~cm})$, estimated wind speed $U_{a}(200 \mathrm{~cm} / \mathrm{s})$, estimated roughness length $Z_{0}(2 \mathrm{~cm})$, von Karman's constant $k$, the constant vapor density at the dewpoint level $V_{a}$ and the surface vapor density $V_{s}$. The calculation of the water flux toward the surface in the peat employed the value of the mean hydraulic conductivity $K_{w}$ between calculation nodes 1 and 2, water head $H$ and the node spacing $\mathrm{d} Z$. In addition, equation set (1) uses the water volume fraction $X_{w}$, model time step d $t$ and water density $\rho_{w}$.

Vapor flux from the atmosphere:

$$
W_{\mathrm{air}}=\left[k^{2} U_{a} / \log \left(Z_{a}-Z_{a}\right)\right]\left[\left(V_{a}-V_{s}\right) / \rho_{w}\right]
$$

Water flux in peat toward surface:

$$
W_{\text {soil }}=K_{w}[H(2)-H(1)] / \mathrm{d} Z \text {. }
$$

New water volume fraction at surface:

$$
X_{w}(1)=X_{w}(1)+\left[W_{\text {air }}+W_{\text {soil }}\right] \mathrm{d} t .
$$

Both $W_{\text {air }}$ and $W_{\text {soil }}$ are in units of velocity, and are implicitly also expressible in volume per unit area per unit time. Therefore, when summed or integrated over time, the result is a change in the surface water volume fraction.

\subsection{Thermal Properties}

Regression of Kersten's [2] data for the Fairbanks Peat yielded a simple expression for thermal conductivity as a function of the water volume fraction. The standard error of this estimate is $0.08 \cdot 10^{-3} \mathrm{cal} \mathrm{cm}^{-1} \mathrm{~s}^{-1}{ }^{\circ} \mathrm{C}^{-1}$. Equation set (2) outlines the methods used to estimate transient thermal properties. The peat was assigned a porosity $X_{p}$ of 0.8 for the calculations. Thermal conductivity:

$$
K_{t}=0.027 \cdot 10^{-3}+1.383 \cdot 10^{-3} X_{w} .
$$

Volumetric heat capacity:

$$
C_{t}=0.6\left(1-X_{p}\right)+X_{w}
$$

Thermal diffusivity:

$$
D_{t}=K_{t} / C_{t} \text {. }
$$




\subsection{Water Properties}

Sturges [6] observed that a peat with pore volume fraction of $80 \%$ lost half of its water volume when subjected to a tension of one atmosphere. The saturated hydraulic conductivity $K_{o}$ for this material was $2.0 \cdot 10^{-7}$ $\mathrm{cm} / \mathrm{s}$, which is exceptionally low compared to the range of $1.4 \cdot 10^{-4}$ to $2.9 \cdot 10^{-4} \mathrm{~cm} / \mathrm{s}$ commonly used in drainage design [1]. The value used in the simulation was $1.0 \cdot 10^{-4} \mathrm{~cm} / \mathrm{s}$. The method used to calculate the hydraulic properties of the model peat is outlined in equation set (3).

Model desorption curve:

$$
X_{w}=X_{p} \exp \left(A_{w} H\right) \text {. }
$$

Unsaturated conductivity:

$$
K_{w}=K_{o} \exp \left(A_{k} H\right)
$$

Water capacity:

$$
C_{w}=A_{k} X_{w}
$$

Water diffusivity:

$$
D_{w}=K_{w} / C_{w}
$$

Using values of $1.0 \cdot 10^{-2}$ and $7.0 \cdot 10^{-4}$ for the parameters $A_{k}$ and $A_{w}$, respectively, yields an unsaturated hydraulic conductivity curve that decreases four orders of magnitude between saturation and a tension of one atmosphere; the desorption curve is similar to that measured by Sturges [6] for a similar material. The model soil is only a crude estimate of the field situation, because the porosity of organic materials is extremely variable over both space and time.

\subsection{Diffusion and Advection}

The equations abstracting the coupled heat and water system are given in equation set (4).

Temperature diffusion + water thermal advection:

$$
\partial T / \partial t=\left(1 / C_{T}\right)\left\{\left[\partial\left(K_{T}(\partial T / \partial Z)\right) / \partial Z\right]+\left[U_{w} C_{\nu w}(\partial T / \partial Z)\right]\right\}
$$

Water head diffusion:

$$
\partial H / \partial t=\left(1 / C_{w}\right)\left\{\partial\left[K_{w}(\partial H / \partial Z)\right] / \partial Z\right\} .
$$

Water velocity:

$$
U_{w}=K_{w}(\partial H / \partial Z) .
$$

Here, $T, H, Z, K, C$, and $U$ refer to temperature, head, depth, conductivity, capacity and velocity, respectively, and the subscripts $T$ and $W$ refer to the thermal and water systems. $C_{\nu w}$ represents the volumetric heat capacity of water. The diffusion portions of these equations are solved using a fully 
implicit finite-difference scheme in which a tridiagonal matrix of new temperature and water head values is solved. The effects of water advection are then added by finite-difference approximation at each time step.

\subsection{Vapor Transport Effects}

A vapor diffusivity of $0.274 \mathrm{~cm}^{2} / \mathrm{s}$ was employed in the simulation. After a cycle of vapor diffusion using the methods employed in the thermal and water systems, the node vapor-density changes resulting from transport and new thermal-water equilibrium conditions [5] are summed. The change of the water volume fraction at a node is equivalent to the negative change in vapor density divided by the density of water. This change in the water volume fraction, when multiplied by the latent heat of evaporation and divided by the current volumetric heat capacity, yields the temperature change due to internal evaporation or distillation. This change, when added to the time-step advection effect and the diffusion solutions, is the new node-temperature value.

\subsection{Initial Conditions}

Soil temperatures were initialized at each calculation node by linear interpolation between the field-measurement levels. The water system is initialized by specifying the air volume fraction $X_{a}$ as a function of depth $Z$ and porosity $X_{p}$ using

$$
X_{a}=0.5 X_{p} \exp (-3 Z / 50) .
$$

Because the volume fractions for soil, water and air must sum to unity, the soil volume fraction remains fixed at $1-X_{p}$, and the water volume fraction is obtained from $X_{p}-X_{a}$. The initial water head $H$ is calculated by

$$
H=\log \left(X_{w} / X_{p}\right) / A_{w} .
$$

Eq. (6) is also employed to update node values as the water content changes due to evaporation and distillation. The initial water state is one of moderate dryness at the surface, in line with a qualitative field observation.

\subsection{The Model Queue}

Each iteration of the model begins by updating the upper boundary values, followed by diffusion of water vapor, water head and temperature. The effects of advection and evaporation-distillation are then added. Water head must be recalculated after the evaporation losses or distillation additions. These effects are not calculated at the surface; they are assumed to be included in the observed surface time series, which is used as an upper boundary condition. 


\section{Model Results}

The hourly temperature, volume fraction and temperature change due to conduction, advection and latent heat processes were tabulated for hours 1-23 of the simulation. The observed and simulated thermal regimes at 5,10 , and $20 \mathrm{~cm}$ are compared in Fig. 3. Unlike the situation at other depths, the observed temperature depression at the $20-\mathrm{cm}$ level is greater than that of the simulation during the period in which heating occurs at the surface. In the time series obtained from the simulation, the temperature depression also occurs at the 15-cm level (Fig. 4).

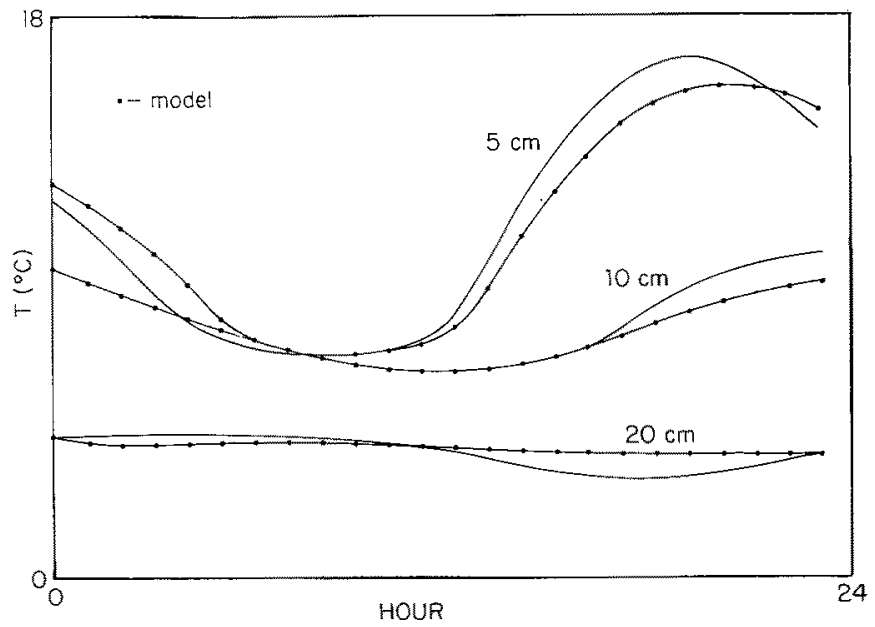

Fig. 3. Observed and simulated thermal time series

Thermal data from the model were used to construct Fig. 5, in which isotherms are displayed on a time-depth grid. Given the correspondence between the observed and simulated thermal regimes at 5,10 , and $20 \mathrm{~cm}$, this mapping may be a realistic estimate of the thermal field below the measurement levels. The $1^{\circ}, 2^{\circ}$ and $3^{\circ} \mathrm{C}$ isotherms rise in elevation, illustrating that cooling occurred in the lower two-thirds of the peat cover throughout the observation period.

Finally, output from the model was used to construct Fig. 6, in which temperature change due to conduction, advection and evaporation are plotted as functions depth for the period of 1500-1600 hours in the model. This diagram shows conditions typical of the period in which warming occurs at the surface. Cold-water advection is the dominant process countering conduction; evaporation limits temperature maxima near the surface. 


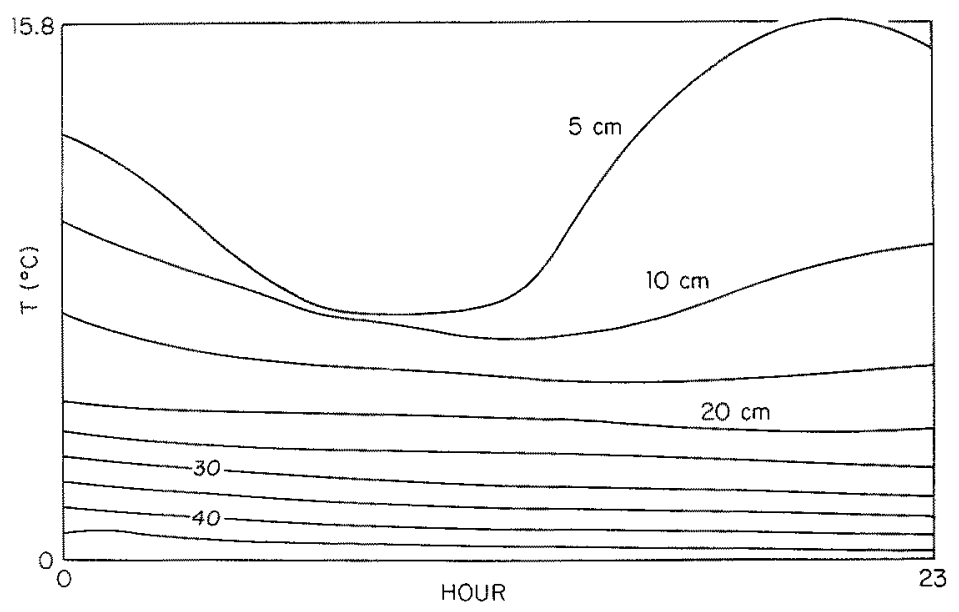

Fig. 4. Thermal time series at all calculation nodes

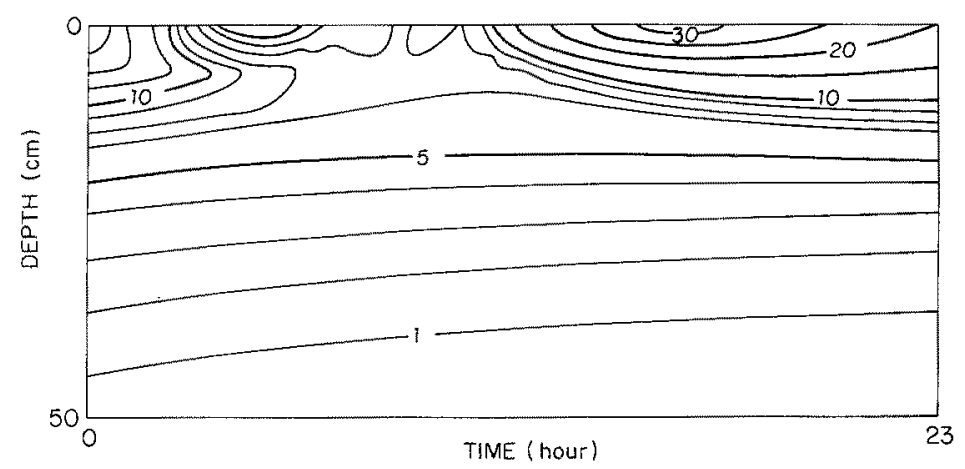

Fig. 5. Model isotherms in peat cover

If finite-difference methods are used to calculate effective thermal diffusivity from temperature records obtained while these conditions dominate, the values are near zero or negative.

\section{Conclusion}

The thermal regime observed within a peat layer overlying a melting ice core could only be produced by cold-water advection or internal evaporation. The simulation suggests that advection of cold water from the melting ice/ peat interface toward the zone of near-surface evaporation retards con- 
ductive heat transfer toward the ice core. Evaporation limits the maximum temperature in the upper part of the peat cover.

Because the ratio of the heat of evaporation to that of fusion is approximately 7.5 for water, and advective cooling occurs as meltwater moves from the ice/peat interface upward to the surface-evaporation zone, the processes involved in coupled flow are extremely effective for retarding ablation. These processes, active during each large-amplitude heating event in the brief arctic summer, have been an important factor in preserving the palsas as relatively stable geomorphic features for more than three years.

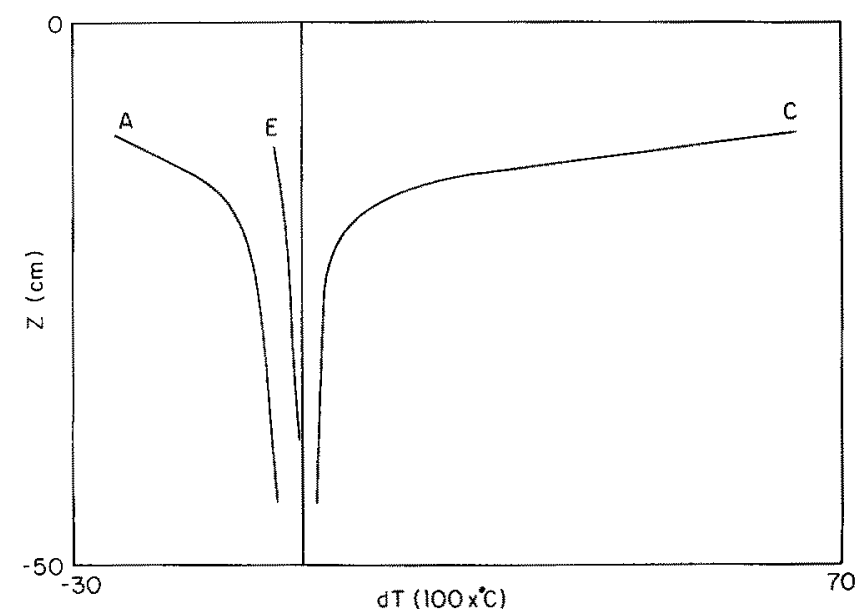

Fig. 6. Model temperature changes produced by conduction $(C)$, advection $(A)$, and evaporation $(E)$ in the hour ending at 1600 model time

\section{Acknowledgements}

Field measurements were made possible by a U.S. National Science Foundation grant subcontract from Pennsylvania State University to the University of Michigan (TPSUUM-22206-131). Data reduction and computer modeling were funded by a U.S. National Science Foundation grant (DPP-8117124) to the University of Michigan entitled "Dynamics of Growth and Decay of Palsas and Related Frost Mounds in Central and Northern Alaska". The figures were drawn by Derwin Bell, Department of Geological Sciences, University of Michigan.

\section{References}

1. Hillel, D.: Soil and Water. New York: Academic Press 1971.

2. Kersten, M. S.: Thermal Properties of Soils. Bulletin 29, Engineering Experiment Station, Institute of Technology, University of Minnesota, 1949. 
3. Nelson, F. E., Outcalt, S. I., Goodwin, C. W., Hinkel, K. M.: Diurnal Thermal Regime in a Peat-Covered Palsa, Toolik Lake, Alaska. Arctic (in press).

4. Outcalt, S.: The Effects of Iteration Frequency on a Model of Ice Segregation. Engineering Geology 13, 111-124 (1979).

5. Rose, C. W.: Agricultural Physics. London: Pergamon Press 1969.

6. Sturges, D. L.: Hydrologic Properties of Peat from a Wyoming Mountain Bog. Soil Science 106, 262-264 (1968).

7. Thie, J.: Distribution and Thawing of Permafrost in the Southem Part of the Discontinuous Zone in Manitoba. Arctic 27, 189-200 (1974).

8. Zoltai, S. C.: Southern Limit of Permafrost Features in Peat Landforms, Manitoba and Saskatchewan. Geological Association of Canada, Special Paper 9, 305-310 (1971).

Authors' address: S. Outcalt and F. Nelson, Department of Geological Sciences, University of Michigan, Ann Arbor, MI 48109, U.S.A. 